\title{
How to Keep Economic Growing while Reducing Carbon Emission? - A Research on Gansu Province in China
}

\author{
Jie Shang $^{1}$ \\ ${ }^{1}$ School of Economics, Northwest University for Nationalities, Lanzhou, China \\ Correspondence: Jie Shang, Lecturer, School of Economics, Northwest University for Nationalities, Lanzhou, China. \\ E-mail: shangjie@163.com
}

Received: April 22, 2015

Accepted: May 6, 2015

Online Published: May 14, 2015

doi:10.5430/ijba.v6n3p86

URL: http://dx.doi.org/10.5430/ijba.v6n3p86

This research was supported by The Fundamental Research Funds for the Central Universities of Northwest University for Nationalities (Grant No. 31920130097)).

\begin{abstract}
There is much research on the relationship of economic growing and carbon emission, but most of them were based on the western countries' data. Few researchers pay attention to the undeveloped areas in western of China. As Gansu is a typical province, who's economic development lagged behind while the quality of carbon emissions are large. In this paper, data of 2003-2013 is collected and least-squares regression is used to analyzed the factors affect the carbon emission in Gansu, the conclusions are that the industrial structural,proportion of heavy industry,and GDP are the three main factors affect carbon emission, and at the end, suggestions on how to keep growing while reducing carbon emission are improved.
\end{abstract}

Keywords: carbon emissions, economic growth, emission reduction

\section{Introduction}

The relationship of economic growing and carbon emission was studied in 1990s. It was found that on the first stage of development, the carbon emission grow along with the economic growth; but when GDP has reach a inflection point, GDP grow, emission reduce. This phenomenon was called "Environmental Kuznets Curve".

Grossman and Krueger (1991) discovered that when the per-capita incomes has reach 4,000-5,000\$, environment pollution inclined to reduce. Research of Panayotou (1993) showed that when the per-capita incomes has exceed 10000 , the country will reduce the proportion of heavy industry and turn to tertiary industries. This conclusion proved the "Environmental Kuznets Curve".

Holtz-Eakin and Selden (1995) also agree on this point, but some other researches have a different option. Lieb (2004) consider the EKC has some limitation when the dynamic pollution was considered. Thophile Azomahou (2005) found that carbon emission grow all the time when economic grow. There are few researches on the undeveloped area, and how to reduce pollution while keep GDP growing is unknown.

Chen, Anping (2013) analyses the impact of $\mathrm{CO}_{2}$ reduce policy in differential regional. They found that labor market policies are more useful than Standard fiscal policies in offsetting the adverse effects. Kapusuzoğlu, Ayhan (2014) examined the relationship between GDP and CO2 emissions worldwide. They found that there is no causality relationship exists in the OECD and in European countries. Musolesi (2014) studied the relationship between carbon emission and economic development in North America and Oceania, and discover that "the country-specific time related factors weight more than income in driving the northern EU Environmental Kuznets. Overall, the countries differ more on their carbon-time relation than on the carbon-income relation which is in almost all cases monotonic positive" (Note 1) 


\section{Overview of Energy Consumption and Economics in Gansu Province}

\subsection{Trend of Energy Consumption in Gansu Province}

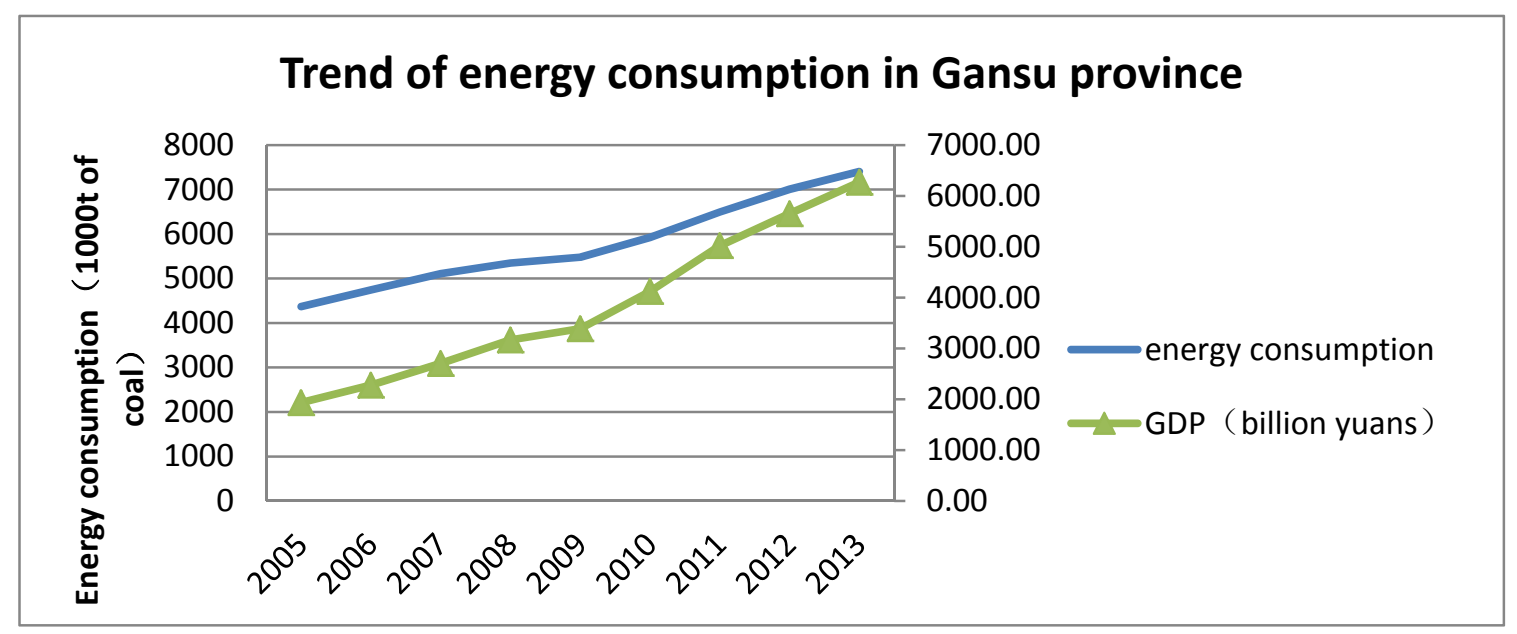

Figure 1. Trend of energy consumption in Gansu province

Figure 1 shows that after 2011, the growth of energy consumption faster than growth of GDP in Gansu province, it means the development more depend on energy consumption than before.

\subsection{Change of Industry Construction in Gansu Province}

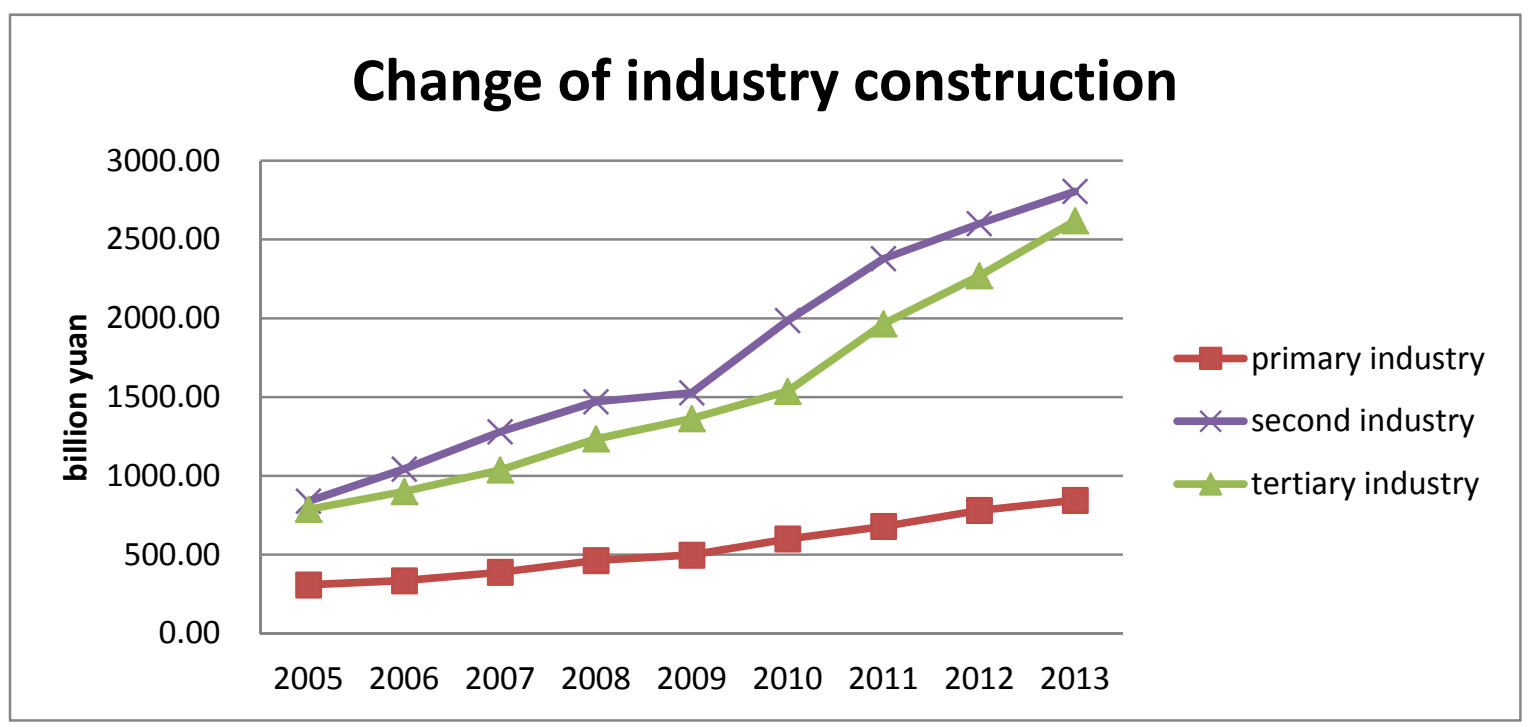

Figure 2. Change of industry construction in Gansu province

Figure 2 shows that, in Gansu province the economic development mainly rely on the second industry, in recent years the speed of second industry is obviously faster than the tertiary industry. As the development of second industry relys on the energy much more, the volume of emission is high. 


\subsection{Energy Consumption of Each Industry}

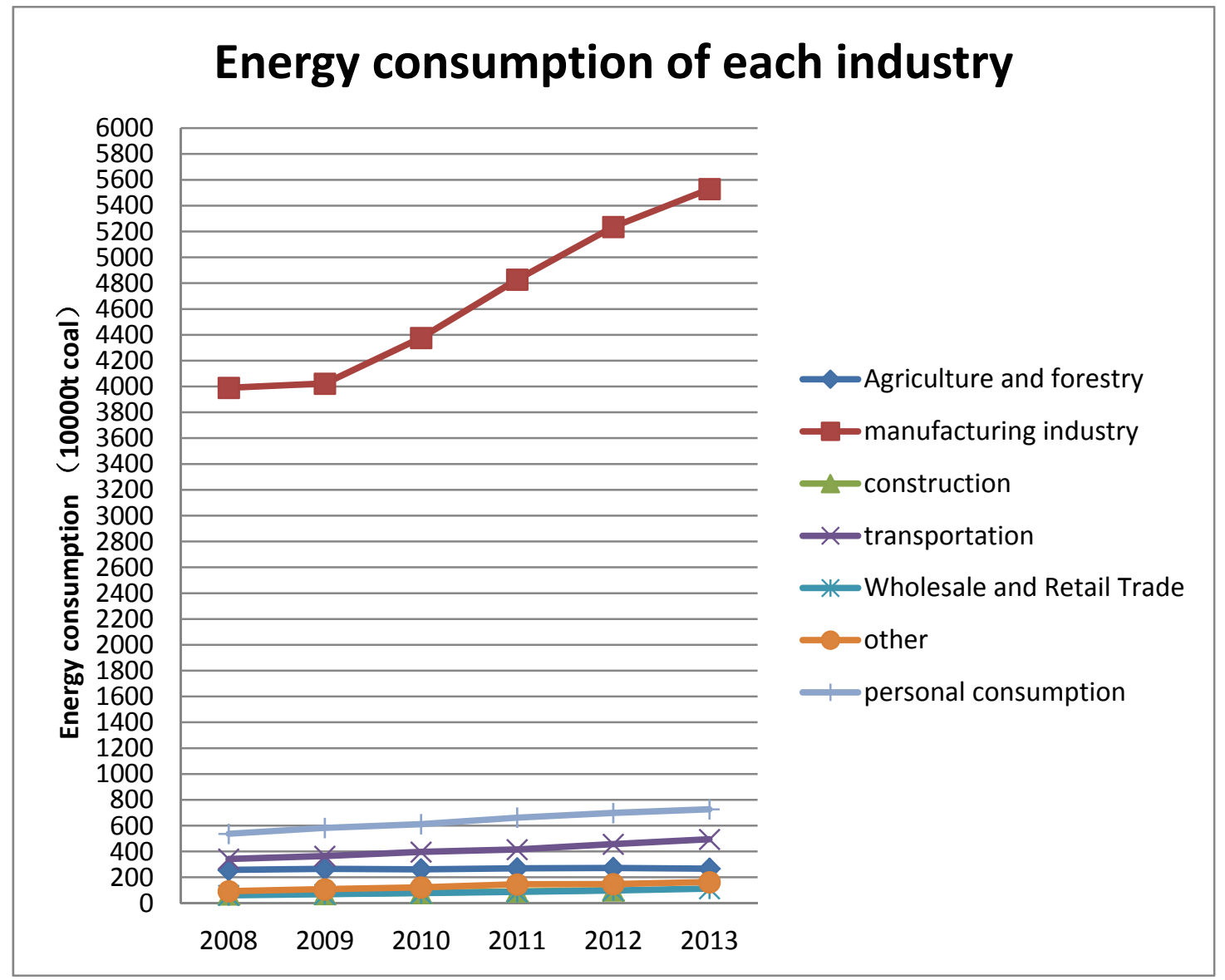

Figure 3. Energy consumption of each industry

It is obvious that energy consumption of manufactory industry is much higher than other industry. And it growled rapidly after 2009 .

\subsection{Comparison of Energy Consumption Elasticity Ratio between Gansu and the State}

Energy consumption elasticity ratio is an important index of the relationship between energy consumption and economic development. Energy consumption elasticity ratio=the growth rate of energy consumption/ the growth rate of GDP. Higher the ratio is, stronger the dependence is. 


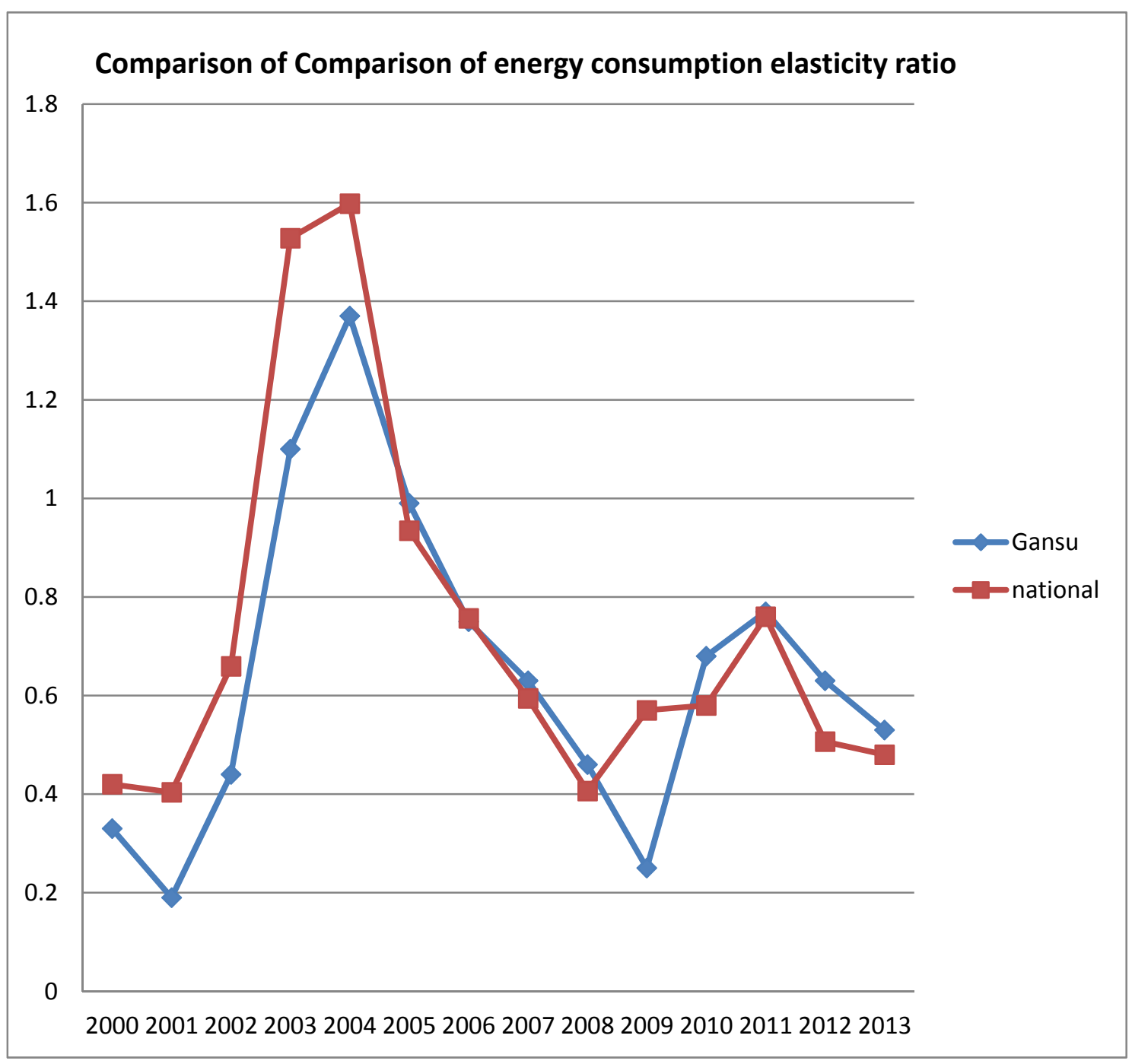

Figure 4. Energy consumption elasticity ratio

From 2000 to 2004, the energy consumption elasticity ratio of Gansu growled rapidly, it reached the peak of 1.37, in the after 5 years it keep declining; in 2009,it was 0.25 ; but in 2009 to 2001 ,it rised slowly, indicating the development of high energy consuming industries in Gansu province is still faster than the low energy industry development.

Compared with the whole state, the trend of Gansu energy consumption elasticity and the like, for most of the years before 2010, the energy consumption elasticity coefficient in Gansu is lower than the national level, but after 2010, the elastic coefficient of energy consumption in Gansu province will continue to higher than the national average level.

\section{Panel Regression Analysis of Emissions and Economic Factors}

\subsection{Theoretical Hypotheses}

There is mush factors affect economic development, such as economic development, industry construction, civilization and so on. The most important factors would be analyzed.

First is the economic development. Energy consumption usually grow when economic grow. In general, in the early stage of industrialization, Carbon emission per capita grow rapidly, for economic highly depend on the facial energy at this stage; in the later stage of industrialization, the industry construction changed, the dependence decreased, relationship between economic and emission turned weaken. Although China has enter the mid-and post-industrialization, Gansu is still in the early stage of industrialization, that means the demand of energy will keep 
growing in a long term in Gansu.

The second factor is industry constriction. Emission of the primary industry and the second industry comparably low, while the tertiary industry's emission usually higher. The output of the second industry is $47 \%$ in Gansu, the proportion is much higher than the national average level.

The third factor is the structure manufacturing industry. Heavy industry refers to the industry provide material and technical foundation for the various sectors of the industry, including metallurgy, machinery, energy, chemical, building materials. Much research show that heavy industry inclined to discharge more carbon per unit of GDP. The proportion of heavy industry is higher than the average level.

The forth factor is the level of urbanization. Compared with the way of life in rural, urban residents' life style has the characteristics of high carbon emissions. In 2000-2012, the urbanization rate raised 1.13 percentage points per year on average in Gansu. In 2012, Gansu's urban resident population is 9.988 million; the urbanization rate reached $38.75 \%$. But the urbanization level is still lower than the national average of $53.7 \%$, with the improving of urbanization rate in further, there would be more carbon be discharged.

\subsection{Index Selection}

As to the above theoretical analysis and the availability of data .Emissions of carbon dioxide (carbon) is the explanatory variables,

And per capita GDP (gdpper) represent the economic growth; industrial added value accounted for the proportion of GDP (cyjg) represent the industrial structure; the proportion of heavy industrial output value in total industrial output value (gyjg) represent the manufacture industrial structure; the non-agricultural population proportion of the total population (czhl) represents the urbanization rate, all the data come from the " GANSU DEVELOPMENT YEARBOOK".

\subsection{Empirical Analysis}

In order to get the ideal model of relationship between carbon dioxide emissions and economic development of Gansu, this paper uses the time series analysis. First step is the stationary test, the ADF unit root test is used, results are as follows:

Table 1. Result of series unit root test

\begin{tabular}{llllll}
\hline Variable & Times of differential & $(\mathrm{C}, \mathrm{T}, \mathrm{K})$ & $\mathrm{DW}$ & ADF & Conclution \\
\hline carbon & 0 & $(0,0,1)$ & 1.842 & $3.235^{*}$ & $\mathrm{I}(0)$ \\
\hline cyjg & 1 & $(0,0,1)$ & 1.954 & $-2.125^{*}$ & $\mathrm{I}(1)$ \\
\hline gyjg & 1 & $(0,0,1)$ & 1,798 & $-1.576^{*}$ & $\mathrm{I}(1)$ \\
\hline czhl & 1 & $(0,0,1)$ & 1.680 & $-2.401^{*}$ & $\mathrm{I}(1)$ \\
\hline gdpper & 1 & $(0,0,1)$ & 2.942 & $-0.559^{* *}$ & $\mathrm{I}(1)$ \\
\hline
\end{tabular}

Note: ${ }^{*}, * *, * * *$ represent significance in $10 \%, 5 \%, 1 \%$.

The influence of lagged variables are considered, finally we get the estimation equation:

$$
\begin{aligned}
& \text { carbon }=0.08 * \text { gdpper }(-1)+11293.35 * \operatorname{cyjg}(-1)+6483.08 * \operatorname{gyjg}(-1)+1687.46 * \operatorname{czhl}(-1) \\
& \begin{array}{lll}
(0.0337) & (0.0313) \quad(0.0303)
\end{array} \\
& \mathrm{R}^{2}=0.94 \quad \text { D. W }=2.35 \quad \text { s.e }=7.68 \quad \mathrm{~T}=30
\end{aligned}
$$

The regression results show that the heavy industrial structure, industrial structure, per capita GDP three variables have significant influence on the carbon emissions in Gansu Province, but the regression coefficient of the urbanization rate is not significant.

\section{Policies and Measures}

\subsection{Change the Energy Structure}

Energy consumption has a direct impact on carbon emissions. In the current energy consumption structure of Gansu province, coal accounted for about $65 \%$, while the clean energy, wind, hydro, natural gas is relatively low. Besides coal and oil, there are natural gas, solar energy, wind energy, hydropower and other clean energy in Gansu province. 


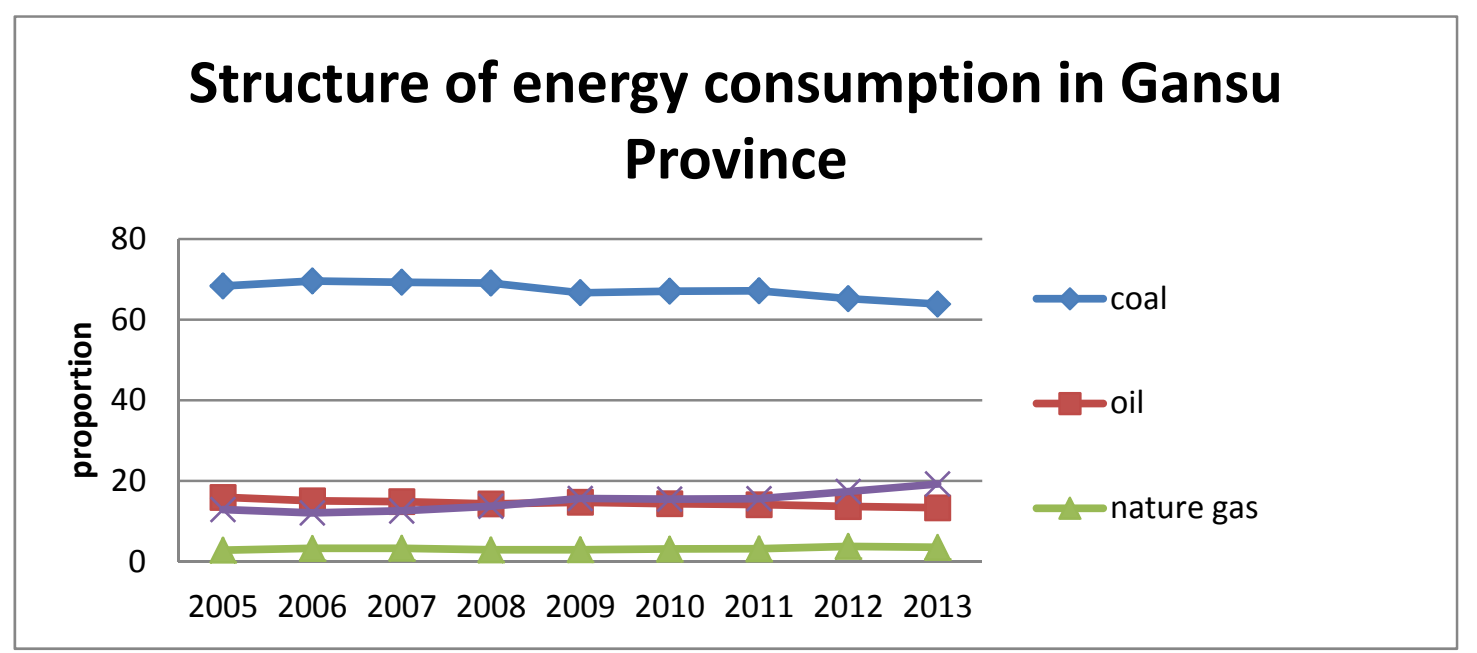

Figure 5. Structure of energy consumption in Gansu Province

From 2005 to 2013, in the energy consumption structure of Gansu province, coal and oil declined slightly, proportion of natural gas almost unchanged, hydro and wind power increased slowly. The proportion of coal consumption decreased from $68.32 \%$ in 2005 to $63.86 \%$ in 2013 , the average was $67.34 \%$; the average proportion of oil is $14.49 \%$, natural gas 3.21\%, hydropower and wind power increased from $12.19 \%$ in 2005 to $19.27 \%$ in 2013 .

First, the wind energy resources in Gansu is 237000000 kilowatts, ranking fifth in the country; second, Gansu is on of the three region which has abundant solar energy in China, the total solar radiation is about $4800 \sim 6400 \mathrm{MJ} / \mathrm{m} 3$ in Hexi, Gannan. Third, in Gansu hydropower reserves ranked tenth in the country, but most of them are not developed. Therefore, Gansu has the potential to improve the energy consumption structure to reverse the high energy consumption and high pollution of the mode of economic development.

\subsection{To Optimize the Industrial Structure}

International experience shows that in the period of the per capita GDP rising from $\$ 1000$ to $\$ 3000$, energy, car, house, building materials, communications and other industries always develop rapidly, which will promote the iron and steel, machinery, building materials, chemical industry and other heavy chemical industry and electronic and communication equipment manufacturing develop rapidly. Therefore, Gansu should adjust the industrial structure; reduce high energy consuming industries.

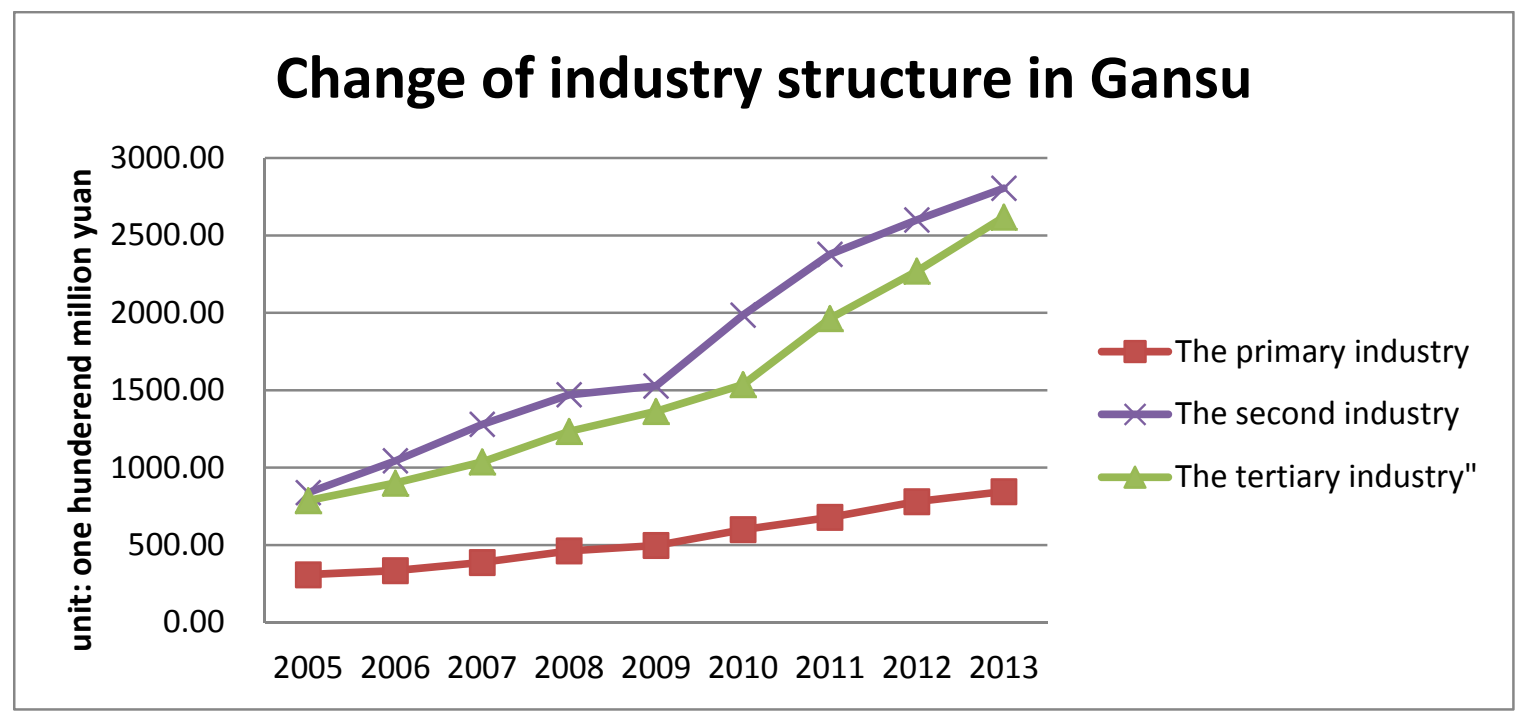

Figure 6. Change of industry structure in Gansu 
On the whole, the proportion of the first industry declined slowly; the proportion of the second industry increased from $43.36 \%$ in 2005 to $48.17 \%$ in 2010 , in 2013 , it dropped again to $44.75 \%$. The proportion of the tertiary industry rise in most of the years, but in 2010 there was also decreased significantly.

So the key to the development of low carbon economy in Gansu province is the adjustion of the investment structure, giving priority to the tertiary industry, reduce the proportion of heavy industry in the industry. Revise "Gansu Industrial Restructuring Directory", develop high and new technology and new materials, new energy, bioindustry, information technology, advanced equipment manufacturing and low carbon industry.

\subsection{Develop CDM Projects}

The CDM project has developed in Gansu in 2002, until July 17, 2014, the total number CDM project approved by Gansu is 269 , accounting for $5.32 \%$ in China. 238 of which have been registered, accounting for $6.26 \%$ of the country. The development of CDM can help Gansu reduce carbon emission from technology and capital two aspects.

\subsection{Establishing Low Carbon Concept in Public}

Research shows that personal consumption can affect energy consumption $45 \%-55 \%$. Consumer behavior is very important to carbon reduce.

As an underdeveloped area, public awareness of low-carbon is generally weak in Gansu. The government should help public to cultivate the low carbon lifestyle by price subsidies for energy-saving products and advertisement.

\subsection{Planting Trees and Grass}

Research shows that per hectare forest absorb about 0.26 to 0.39 tons carbon a year. The "Third national assessment report on climate change" released by China in 2014 pointed out that in current and future the forest carbon sequestration is an important way to reduce carbon emission.

In Gansu the forest coverage rate is low. According to the seventh resources inventory, the forest coverage rate in Gansu is $11.28 \%$, ranked twenty-seventh in the country. Strengthen the management and construction of grassland, the establishment of wetland ecological system is an important way to reduce carbon emissions, and also an important guarantee to promote the sustainable development of Gansu.

\section{References}

Ancev, T., \& Harris, M. (2004). Pigou and Coase Re-revisited: Ethics, Norms, and Markets Implications for Environmental and Resource Economics. Paper Selected for the 33th Australian Confer-ence of Economists.

Bouchery, Y., \& Fransoo, J. (2015). Cost, carbon emissions and modal shift in intermodal network design decisions. International Journal of Production Economics, 164(6), 388-399.

Chen, A.P., Groenewold, N., \& Hagger, A.J. (2013). The regional economic effects of a reduction in carbon emissions. Australian Journal of Agricultural \& Resource Economics, (10), 483-500.

Coase, R. (1960). The Problem of Social Cost. Journalof Law and Economics, 3(1), 1-44.

Cropper, M., \& Oates, W. (1992). Environmental Economics: A Survey. Journal of Economic Literature, 30(2), 675-740.

Dales, J.H. (1968). Pollution, Property and Prices. Toronto: University of Toronto Press.

Fahimnia, B., Sarkis, J., Choudhary, A., \& Eshragh, A. (2015, June). Tactical supply chain planning under a carbon tax policy scheme: A case study. International Journal of Production Economics, 164(6), 206-215.

Grossman, G.M., \& Krueger, A.B. (1991). Environmental Impact of a North American Free Trade Agreement. NBER Working Paper, No.3914.

Grossman, S., \& Hart, O. (1986). The Costs and Benefits of Ownership: A Theory of Vertical and Lateral Integration. Journal of Political Economy, 94, 691-719.

Humphrey, D., \& Moroney, J. (1975). Substitution among capital, labor and national resource products in American manufacturing. Journal of Political Economy, (83), 57-82.

Intergovemnental Panel on Climate Change. (2007). Climate change. Synthesis report 2007, pp.30-33.

Jorgenson, D.W., \& Wilcoxen, P.J. (1990). Environmental regulation and U.S. economic growth. The Rand Journal of Economics, (21).

Kapusuzoğlu, A. (2014). Causality Relationships between Carbon Dioxide Emissions and Economic Growth: Results 
from a Multi-Country Study. International Journal of Economic Perspectives, (6), 5-15.

Kivyiro, P., \& Arminen, H. (2014). Carbon dioxide emissions, energy consumption, economic growth, and foreign direct investment: Causality analysis for Sub-Saharan Africa. Energy, 74(9), 595-606.

Musolesi, A., \& Mazzanti, M. (2014). Nonlinearity, heterogeneity and unobserved effects in the carbon dioxide emissions-economic development relation for advanced countries. Studies in Nonlinear Dynamics \& Econometrics, 18(5), 521-541.

Tapio, P. (2005). Towards A Theory of Decoupling: Degrees of Decoupling in the EU and the Case of Road Traffic in Finland between 1970 and 2001. Transport Policy, 12(2), 137-151.

Yang, Z.H., \& Zhao, Y.L. (2014). Energy consumption, carbon emissions, and economic growth in India: Evidence from directed acyclic graphs. Economic Modelling, 38(2), 533-540.

\section{Note}

Note 1. Musolesi, Antonio, Mazzanti, Massimiliano, "Nonlinearity, heterogeneity and unobserved effects in the carbon dioxide emissions-economic development relation for advanced countries." Studies in Nonlinear Dynamics \& Econometrics, 2014,1(9), Vol. 18 Issue 5, 521-541. 